\title{
Sensitivity Analysis of Physically Doped, Charge Plasma and Electrically Doped TFET Biosensors
}

\author{
Arpita Biswas $^{1} \cdot$ Chithraja Rajan $^{1}$ • Dip Prakash Samajdar ${ }^{1}$ \\ Received: 20 July 2021 / Accepted: 10 October 2021 / Published online: 21 October 2021 \\ (C) Springer Nature B.V. 2021
}

\begin{abstract}
TFET based label-free biosensors are fast, sensitive and more power efficient as compared to CMOS biosensors, which are prone to short channel effects (SCEs). However, literature is flooded with various TFET biosensors that have become the reason of dilemma for researchers during pandemic situations like COVID-19. Therefore, in this work, a physically doped (PD), charge plasma (CP) and electrically doped (ED) dielectric modulated (DM) TFET based label-free biosensors are compared, which cover almost the entire range of doping and junctionless devices. Also, we found that the ED based TFET biosensors provide better current sensitivities of $5.10 \times 10^{7}, 4.77 \times 10^{8}$ and $7.11 \times 10^{8}$ for biomolecules with $\mathrm{K}=12$, positive charge $=1 \times 10^{13} \mathrm{C} /$ $\mathrm{cm}^{2}$ and negative charge $=-1 \times 10^{13} \mathrm{C} / \mathrm{cm}^{2}$ respectively. Hence, ED-DM-TFET based biosensors can act as promising candidates to provide better detection and identification quality.
\end{abstract}

Keywords TFET $\cdot$ Biosensor $\cdot$ Physically doped (PD) $\cdot$ Charge plasma (CP) $\cdot$ Electrically doped (ED)

\section{Introduction}

The common human coronavirus $(\mathrm{CoV})$, which infects millions of people every year are basically of two types: alpha $(229 \mathrm{E}$, NL63) and beta (OC43, HKU1, SARS-CoV, MERS-CoV). SARS (severe acute respiratory syndrome) CoV affected 8000 people in 2003 and MERS (Middle East respiratory syndrome) $\mathrm{CoV}$ infected more than 1700 people in 2012 [1, 2]. Now, the latest one, SARS-CoV-2, which is responsible for the rapid transmission of COVID (coronavirus disease) in 2019, turned into pandemic as it infected 230 million and killed 4.72 million people around the world as of September 2021. SARS-CoV-2 can spread directly from person to person through sneezing, coughing and talking within a six feet distance limit or through the indirect transmission from formites on which infection lasts for hours. Therefore, the rate of SARS-CoV-2 spread and death

Dip Prakash Samajdar

dipprakash010@gmail.com

Arpita Biswas

arpitabiswas18919@gmail.com

Chithraja Rajan

rajan.chithraja@gmail.com

1 PDPM Indian Institute of Information Technology, Design and Manufacturing, Jabalpur, Madhya Pradesh, India is much more as compared to the other CoVs as this virus damages respiratory system and fever, dry cough, shortness of breath are some of the symptoms which take 2-14 days to show its deadly effects [3]. Therefore, this is an alarming situation, where each individual has been instructed to wear a mask and maintain social distancing along with personal hygiene. Meanwhile, medical practitioners are searching for fast and accurate test kits, that could detect the infected persons and isolate them to stop transmission. However, the present reverse transcription polymerase chain reaction (RT-PCR) kits are slow and costly as they transform RNA to complementary DNA (C-DNA) and then measure the specific RNA amount by monitoring C-DNA amplification using PCR technique [4]. Unfortunately, the rapid test kits exhibit some limitations like sensitivity and wide deviation of test results (34 \%-80\%), showing both false negative results and false positive results. Also, these rapid test kits can detect COVID only when someone is recently infected and could not provide any information about other diseases and their symptoms. Further, these kits rely on simultaneous capture and detection of the virus and so there is a possibility to miss the patients who have recovered from COVID-19. Therefore, the lack of accurate rapid test kits drove researchers to find suitable alternatives for the detection of SARS-CoV-2 and other such diseases in future.

Certainly, label-free dielectric modulated (DM) FET biosensors are one such alternative as they are capable to detect biomolecules with different dielectric constant values and are 
Fig. 1 SARS-CoV structure [3]

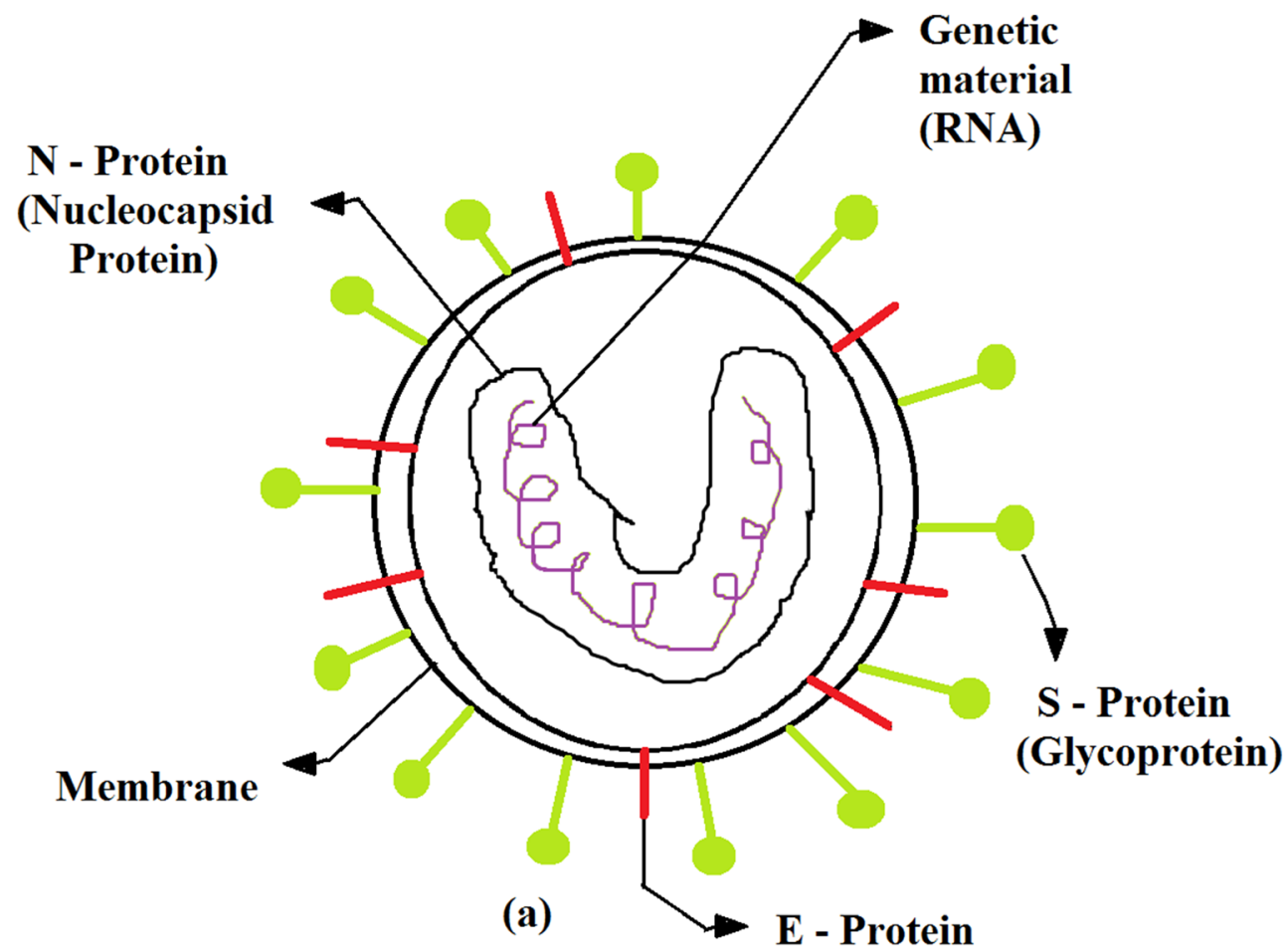

Virus structure

cost efficient as compared to the existing technologies [5-9]. Also, $\mathrm{TiO}_{2}$ nanowires discussed in literature are good examples of glucose and vitamin detections using novel device techniques $[10,11]$. SARS-CoV-2 structure is composed of multiple proteins such as spike (S), membrane (M), envelope (E) and hemagglutinin-esterase (HE) as shown in Fig. 1. The $\mathrm{S}$-protein has dielectric values ranging from 1 to 4 that could be easily detected from label-free DM-FET biosensors. Also, RNA transformed to C-DNA would have dielectric values ranging from 1 to 64 . There is enough evidence available in literature that many FET based biosensors are effective for detection and diagnosis of COVID-19 [12, 13]. Most of the works are centred on graphene [12] and carbon nanotube [14] based FETs. In addition, many 2-D materials [15] and novel FETs [13] mechanisms are also discussed for COVID detection. However, the CMOS based DM-FET biosensors are not suitable for detection of wide variety of biomolecules as they have limitations like less sensitivity, low $\mathrm{I}_{\mathrm{ON}} / \mathrm{I}_{\mathrm{OFF}}$ ratio, subthreshold swing (SS) greater than $60 \mathrm{mV} /$ decade, short channel effects (SCEs) and random variations, which would reduce the test kit sensitivity and power efficiency. Alternatively, Tunnel FET (TFET) based DM biosensor provides better sensitivity due to tunneling phenomenon, SS lesser than $60 \mathrm{mV} /$ decade generates higher $\mathrm{I}_{\mathrm{ON}} / \mathrm{I}_{\mathrm{OFF}}$ ratio at low supply voltage [16-18]. However, COVID-19 researchers are always in dilemma to select the appropriate DM-TFET biosensor as literature is flooded with such biosensors describing their applicability and hence, a decision based on proper guidance is required. Therefore, this manuscript is a small effort towards the comparative analysis of three basic structures which include physically doped (PD) [19], charge plasma (CP) and electrically doped (ED) DM-TFET biosensors [20-23]. Particularly,

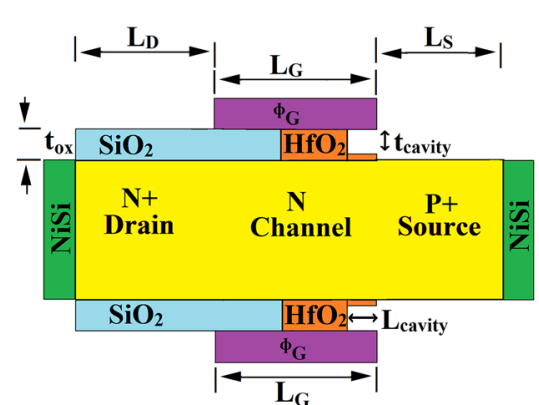

(a)

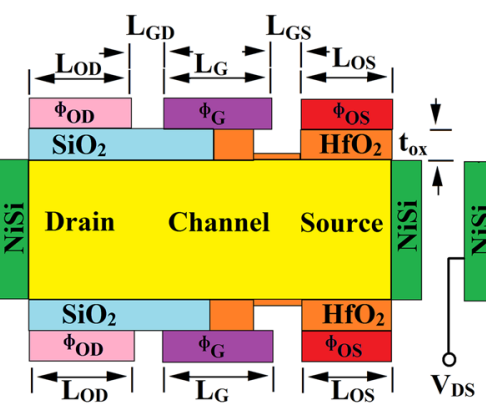

(b)

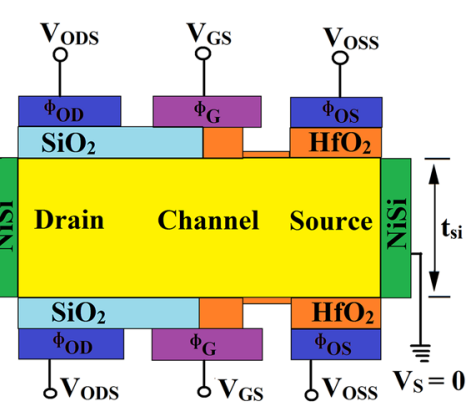

(c)

Fig. 2 (a) PD-DM-TFET (b) CP-DM-TFET (c) ED-DM-TFET based biosensors structure 
Table 1 Design parameter of PDDM-TFET, CP-DM-TFET and ED-DM-TFET based biosensors

\begin{tabular}{lllll}
\hline Parameter Name and Unit & Symbol & $\begin{array}{l}\text { PD-DM- } \\
\text { TFET }\end{array}$ & $\begin{array}{l}\text { CP-DM- } \\
\text { TFET }\end{array}$ & $\begin{array}{l}\text { ED-DM- } \\
\text { TFET }\end{array}$ \\
\hline Drain doping $\left(\mathrm{cm}^{-3}\right)$ & $\mathrm{N}_{\mathrm{A}}$ & $1 \times 10^{20}$ & $1 \times 10^{15}$ & $1 \times 10^{15}$ \\
Source doping $\left(\mathrm{cm}^{-3}\right)$ & $\mathrm{N}_{\mathrm{D}}$ & $1 \times 10^{20}$ & $1 \times 10^{15}$ & $1 \times 10^{15}$ \\
Channel doping $\left(\mathrm{cm}^{-3}\right)$ & $\mathrm{N}_{\mathrm{ch}}$ & $1 \times 10^{17}$ & $1 \times 10^{15}$ & $1 \times 10^{15}$ \\
Overdrive source length (nm) & $\mathrm{L}_{\mathrm{OS}}$ & & 50 & 50 \\
Overdrive drain length (nm) & $\mathrm{L}_{\mathrm{OD}}$ & & 50 & 50 \\
Spacer length, gate to source (nm) & $\mathrm{L}_{\mathrm{GS}}$ & & 5 & 5 \\
Spacer length, gate to drain (nm) & $\mathrm{L}_{\mathrm{GD}}$ & & 5 & 5 \\
Source length (nm) & $\mathrm{L}_{\mathrm{S}}$ & 55 & 55 & 55 \\
Drain length (nm) & $\mathrm{L}_{\mathrm{D}}$ & 55 & 55 & 55 \\
Gate length (nm) & $\mathrm{L}_{\mathrm{G}}$ & 50 & 50 & 50 \\
Overdrive source work function $(\mathrm{eV})$ & $\phi_{\mathrm{OS}}$ & & 5.93 & 4.5 \\
Overdrive drain work function $(\mathrm{eV})$ & $\phi_{\mathrm{OD}}$ & & 3.9 & 4.5 \\
Gate work function (eV) & $\phi_{\mathrm{G}}$ & 4.7 & 4.7 & 4.7 \\
Silicon thickness (nm) & $\mathrm{t}_{\mathrm{si}}$ & 10 & 10 & 10 \\
Oxide thickness (nm) & $\mathrm{t}_{\mathrm{ox}}$ & 5 & 5 & 5 \\
Cavity length (nm) & $\mathrm{L}_{\mathrm{Cavity}}$ & 15 & 15 & 15 \\
Cavity thickness (nm) & $\mathrm{t}_{\mathrm{Cavity}}$ & 3 & 3 & 3 \\
Drain and Source contact & & NiSi & NiSi & NiSi \\
\hline & & & &
\end{tabular}

these three devices cover almost the entire research area of doping and doping-free (junctionless) TFETs and hence [24], this manuscript provides a strong interpretation for the selection of proper device technology for designing rapid and accurate biosensors in future.

\section{Device Structure, Simulation Setup}

The cross-sectional view of PD-DM-TFET, CP-DM-TFET and ED-DM-TFET biosensors are presented in Fig. 1. In PD-DM-TFET (Fig. 2(a)) N+ drain region and the P+ source

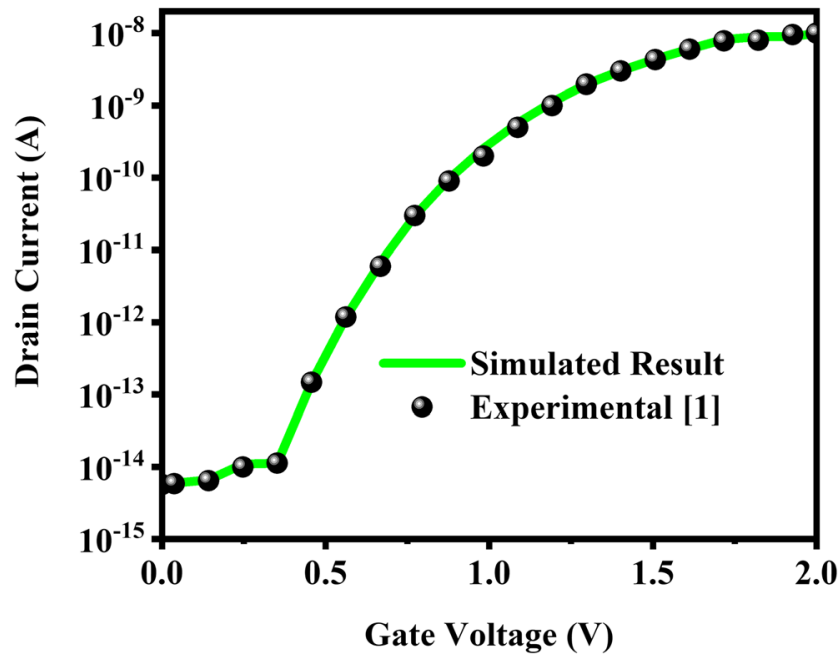

Fig. 3 Calibration of the simulated results with Experimental data [6] region are created through doping where as CP-DM-TFET (Fig. 2(b)) and ED-DM-TFET (Fig. 2(c)) are junctionless devices as there are no physical boundaries between the regions through doping difference. But, in CP-DM-TFET and EDDM-TFET external metal electrodes are placed above the source and drain regions and metal-semiconductor work function difference creates plasma of charge in CP-DM-TFET while opposite potentials applied on electrodes create source and drain in ED-DM-TFET [25]. TFET produces low ON current and high ambipolarity which affects biosensor sensing capability and power requirements. Therefore, hetero dielectric (HD) techniques are adopted by which half of the semiconductor from gate to source is covered with the high-K dielectric $\left(\mathrm{HfO}_{2}\right)$ which improves tunneling at the junction and hence $[26,27]$, provides better ON current where as a low-K dielectric $\left(\mathrm{SiO}_{2}\right)$ in the other half reduces the ambipolar conduction at drain/channel junction.

Further, to introduce body fluid in the biosensor, a test cavity is formed inside $\mathrm{HfO}_{2}$ below gate electrode towards source region where due to dielectric value difference, the band bending at gate/source junction changes. This results in the variation of drain current which when measured confirms the presence/absence of a particular biomolecule. All device physical parameters used in the device simulation are the optimum values obtained from literature and are tabulated in Table 1.

The device fabrication process flow is as follows : Biosensors discussed in this manuscript include simple Silicon based TFET device that can be fabricated with the 

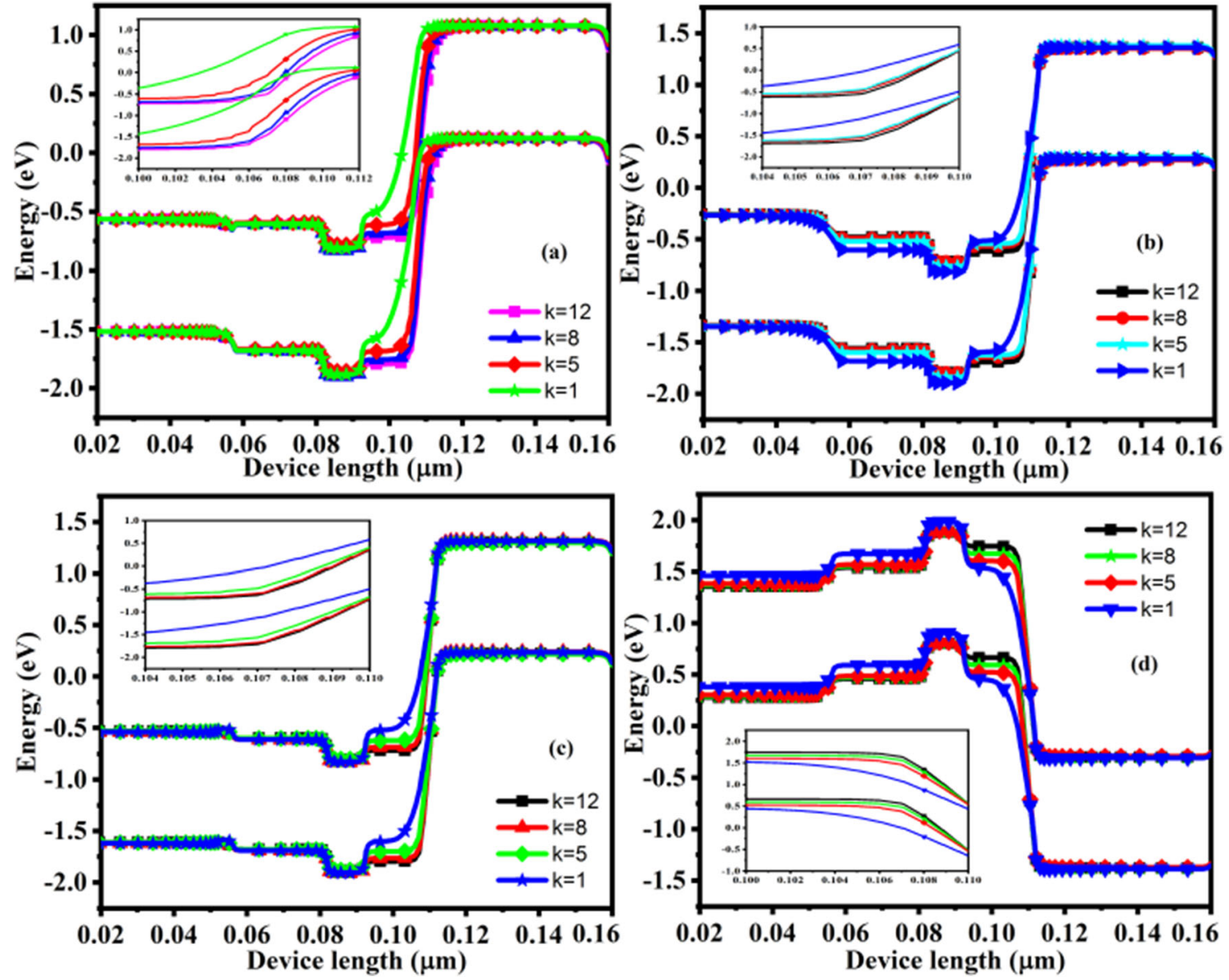

Fig. 4 Energy Band Diagram of (a) n-PD-DM-TFET (b) n-CP-DM-TFET (c) n-ED-DM-TFET (d) p-ED-DM-TFET based biosensors

conventional MOSFET fabrication technologies. In PD biosensor, source and drain regions are created in Silicon substrate by selective window etching and doping by diffusion. Next, hetero dielectric layer can be deposited by liquid phase deposition method: first $\mathrm{SiO}_{2}$ is completely deposited over $\mathrm{Si}$ substrate by dry oxidation process and then, half of the region is selectively etched by photolithography and then the Atomic Layer Deposition (ALD) deposits $\mathrm{HfO}_{2}$ over the remaining portion. In CP and ED devices, additional metal layers are deposited over the oxide layers using metallization techniques. Finally, the test cavities can be formed by dry etching process and below the cavity, $\mathrm{HfO}_{2}$ layer binds the biomolecules.

The device simulations are carried out in Silvaco 2DATLAS TCAD tool. Schottky contact effect is incorporated using Universal Schottky tunneling model (UST), Shockley Read Hall (SRH) and Auger models are used for recombination of carriers. At the tunneling-junction, the carrier generation rate is calculated using non-local band-to-band tunneling (BTBT) and bandgap narrowing (BGN) models. The Fermi Dirac statistics and Klaassen's Unified Low Field Mobility models (KLA) are used to describe the lateral field mobility effect on the device characteristics. The models have been verified with the experimental result in [6] and we found that the simulated results are closely matched with the experimental data as depicted in Fig. 3.

\section{Results and Discussions}

This section deeply investigates the PD-DM-TFET, CP-DMTFET and ED-DM-TFET biosensors and compare their sensing capability for a wide range of biomolecules present in human body, that can be captured through blood, swab or urine samples. These biomolucules having a dielectric value can be charged or neutral and hence, we considered the charge density $\left(-1 \times 10^{13} \mathrm{C} / \mathrm{cm}^{2}-1 \times 10^{13} \mathrm{C} / \mathrm{cm}^{2}\right)$ and $\mathrm{K}(1-12)$ values for the device sensitivity analysis.

\subsection{Sensitivity Comparison for Dielectric Variation}

In this section, we first focus on BTBT process variation at Source/Channel junction for various dielectric constants of biomolecules. Under ON state condition, the energy band diagram (EBD) of n-PD-DM-TFET, n-CP-DM-TFET, $n$ and $p$ ED-DM-TFET based biosensors are shown in Fig. 4(a-d) 

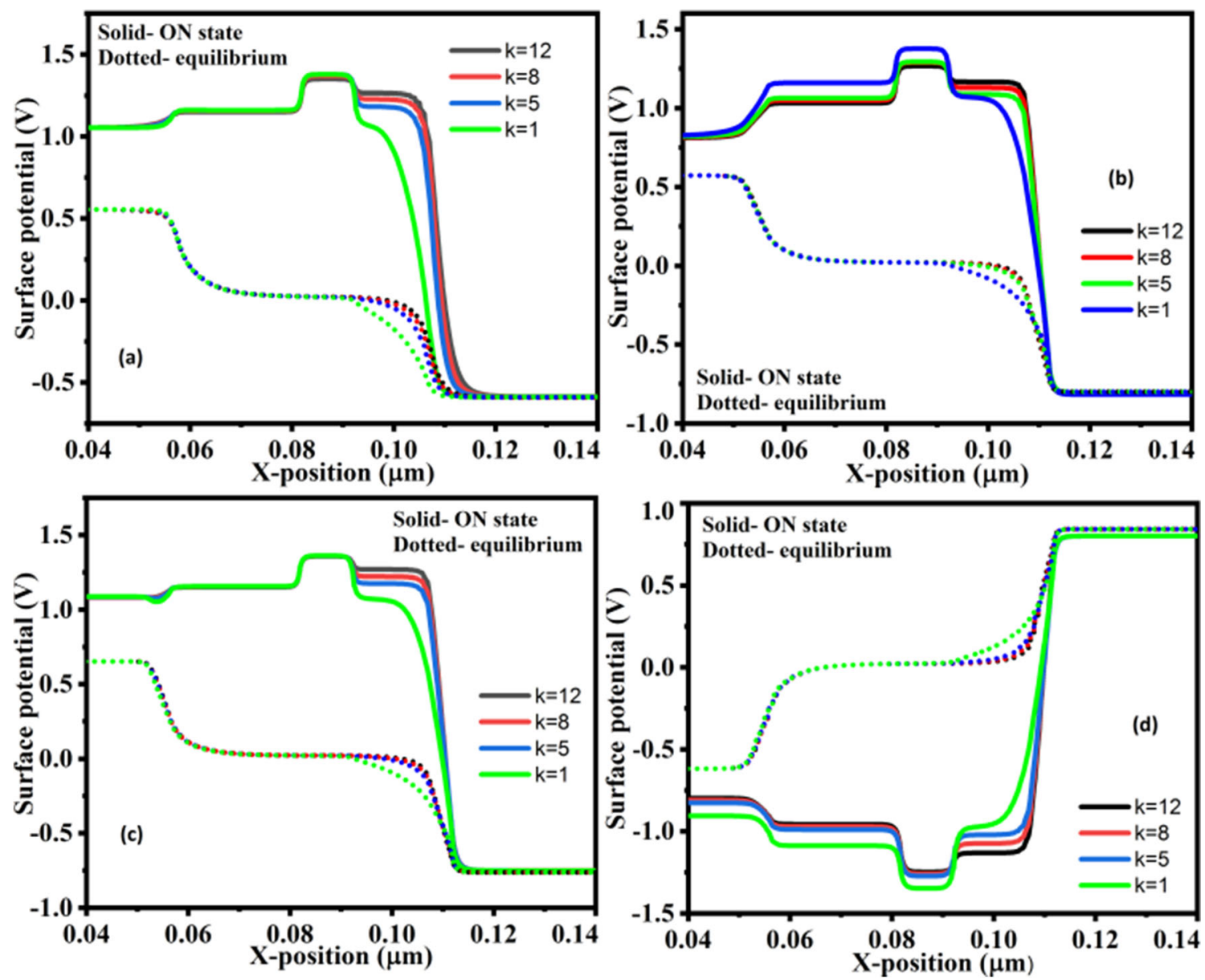

Fig. 5 Surface Potential of (a) n-PD-DM-TFET (b) n-CP-DM-TFET (c) n-ED-DM-TFET (d) p-ED-DM-TFET based biosensors

with neutral charge and variable $\mathrm{K}$ values. In $\mathrm{ON}$ condition, the channel side conduction band $(\mathrm{CB})$ and source side valence band (VB) aligns at source-channel interface. ON state EBD of all the three devices demonstrate that the bandbending increases and barrier width reduces with the increase of $\mathrm{K}$ values. It means that the electrons take less energy to tunnel through the barrier.

Figure 5(a-d) shows the variation in surface potential for three biosensors during $\mathrm{ON}$ and equilibrium conditions. It has been noticed that surface potential is lesser for $\mathrm{K}=1$ (vacant cavity) but in the presence of biomolecules $(\mathrm{K}>1)$, potential increases because the effective gate-capacitance $\left(\mathrm{C}_{\text {eff }}\right)$ of biosensor rises with the dielectric constant value.

Figure 6(a-d) shows the drain current $\left(I_{d}\right)$ characteristics of n-PD-DM-TFET, n-CP-DM-TFET, $n$ and $p$ ED-DM-TFET based biosensors with different values of $\mathrm{K}$. During ON-state, minimum $I_{d}$ is observed for air $(K=1)$. Also, drain current rises with the increment in dielectric constant $(K>1)$ in all the three devices. The peak current values are listed in Table 2 .

For positively-charged biomolecules, the $\mathrm{I}_{\mathrm{d}}-\mathrm{V}_{\mathrm{gs}}$ characteristics of n-PD-DM-TFET, n-CP-DM-TFET, $n$ and $p$ ED-DMTFET based biosensors are shown in Fig. 7(a-d) with constant $\mathrm{K}=5$. In all three $\mathrm{n}$-TFET based biosensors, the drain current
$\left(\mathrm{I}_{\mathrm{d}}\right)$ rises with the increment in positive charge density value of biomolecules but in p-ED-DM-TFET the drain current $\left(\mathrm{I}_{\mathrm{d}}\right)$ decreases with the increment in positive charge density. This could be better explained through EBD of ED-DM-TFET in Fig. 8. Figure 8(a) shows that in n-ED-DM-TFET, bands steepen more at tunneling junction as positive charge increases whereas this effect is reverse in EBD of p-ED-DMTFET (Fig. 8(b)) due to the dominance of opposite charges in both devices. For negatively-charged biomolecules, the $\mathrm{I}_{\mathrm{d}}-\mathrm{V}_{\mathrm{gs}}$ characteristics of n-PD-DM-TFET, n-CP-DM-TFET, $n$ and $p$ ED-DM-TFET based biosensors are shown in Fig. 9(a-d) with the same $\mathrm{K}$ value.

In all three $n$-TFET based biosensors, $I_{d}$ decreases with the increment in negative charge density value of biomolecules but in $\mathrm{p}$-ED-DM-TFET based biosensor, $\mathrm{I}_{\mathrm{d}}$ rises with the increment in negative charge density. This effect is better understood though the EBD of ED-DM-TFET in Fig. 10 and the reason for the reverse trend in p-type and n-type TFET is similar to that explained 8(a) and (b). It can be clearly observed from Fig. 10(b), that in p-ED-DM-TFET, bands steepen more at tunneling junction, whereas the opposite effect is noticed in EBD of n-ED-DM-TFET (Fig. 10(a)) due to the dominance of opposite charges in both devices. The peak 

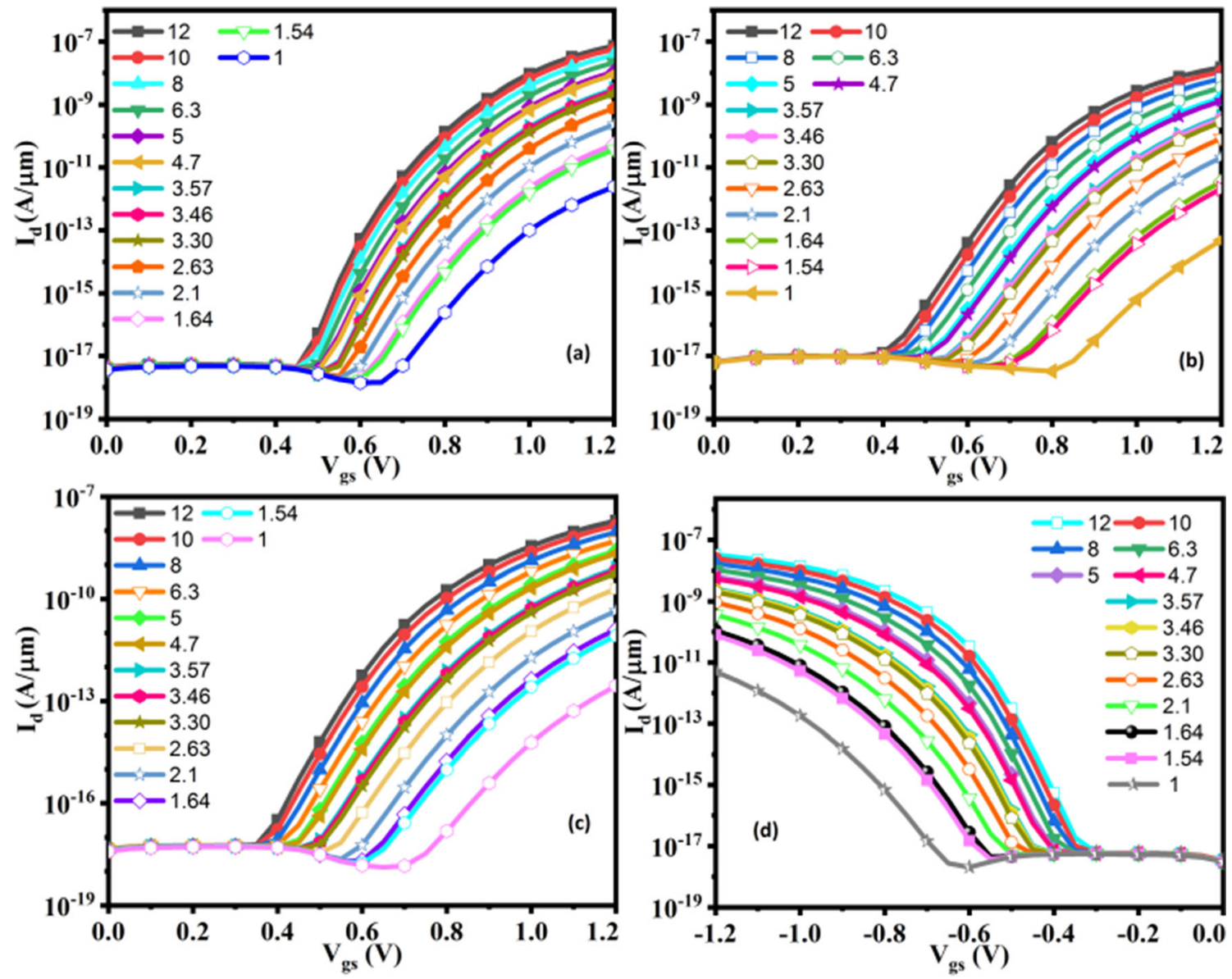

Fig. $6 \mathrm{I}_{\mathrm{d}}-\mathrm{V}_{\mathrm{gs}}$ characteristics of (a) n-PD-DM-TFET (b) n-CP-DM-TFET (c) n-ED-DM-TFET (d) p-ED-DM-TFET based biosensors with different value of dielectric constant $(\mathrm{K})$

Table 2 Peak current value of PD-DM-TFET, CP-DM-TFET and ED-DM-TFET based biosensors for different dielectric constants $(\mathrm{K})$

\begin{tabular}{lcccc}
\hline Dielectric constant $(\mathrm{K})$ & \multicolumn{2}{l}{ Peak current value $(\mathrm{A} / \mu \mathrm{m})$} & \\
\cline { 2 - 5 } & $\mathrm{n}$-PD-DM-TFET & n-CP-DM-TFET & n-ED-DM-TFET & p-ED-DM-TFET \\
\hline 1 & $9.33 \times 10^{-10}$ & $1.99 \times 10^{-10}$ & $4.5 \times 10^{-10}$ & $1.03 \times 10^{-9}$ \\
1.54 & $9.27 \times 10^{-9}$ & $2 \times 10^{-9}$ & $3.9 \times 10^{-9}$ & $4.7 \times 10^{-9}$ \\
1.64 & $1.23 \times 10^{-8}$ & $2.6 \times 10^{-9}$ & $5.1 \times 10^{-9}$ & $5.65 \times 10^{-9}$ \\
2.1 & $3.41 \times 10^{-8}$ & $6.52 \times 10^{-9}$ & $1.27 \times 10^{-8}$ & $1.07 \times 10^{-8}$ \\
2.63 & $7.55 \times 10^{-8}$ & $1.29 \times 10^{-8}$ & $2.56 \times 10^{-8}$ & $1.77 \times 10^{-8}$ \\
3.30 & $1.49 \times 10^{-7}$ & $2.32 \times 10^{-8}$ & $4.64 \times 10^{-8}$ & $2.76 \times 10^{-8}$ \\
3.46 & $1.7 \times 10^{-7}$ & $2.58 \times 10^{-8}$ & $5.19 \times 10^{-8}$ & $3 \times 10^{-8}$ \\
3.57 & $1.85 \times 10^{-7}$ & $2.77 \times 10^{-8}$ & $5.59 \times 10^{-8}$ & $3.17 \times 10^{-8}$ \\
4.7 & $3.44 \times 10^{-7}$ & $4.72 \times 10^{-8}$ & $9.8 \times 10^{-8}$ & $5.04 \times 10^{-8}$ \\
5 & $3.84 \times 10^{-7}$ & $5.26 \times 10^{-8}$ & $1.1 \times 10^{-7}$ & $5.57 \times 10^{-8}$ \\
6.3 & $5.26 \times 10^{-7}$ & $7.79 \times 10^{-8}$ & $1.62 \times 10^{-7}$ & $7.94 \times 10^{-8}$ \\
8 & $5.48 \times 10^{-7}$ & $1.44 \times 10^{-7}$ & $2.37 \times 10^{-7}$ & $1.12 \times 10^{-7}$ \\
10 & $5.89 \times 10^{-7}$ & $1.62 \times 10^{-7}$ & $3.29 \times 10^{-7}$ & $1.49 \times 10^{-7}$ \\
12 & $6 \times 10^{-7}$ & $2.1 \times 10^{-7}$ & $4.23 \times 10^{-7}$ & $1.8 \times 10^{-7}$ \\
\hline
\end{tabular}



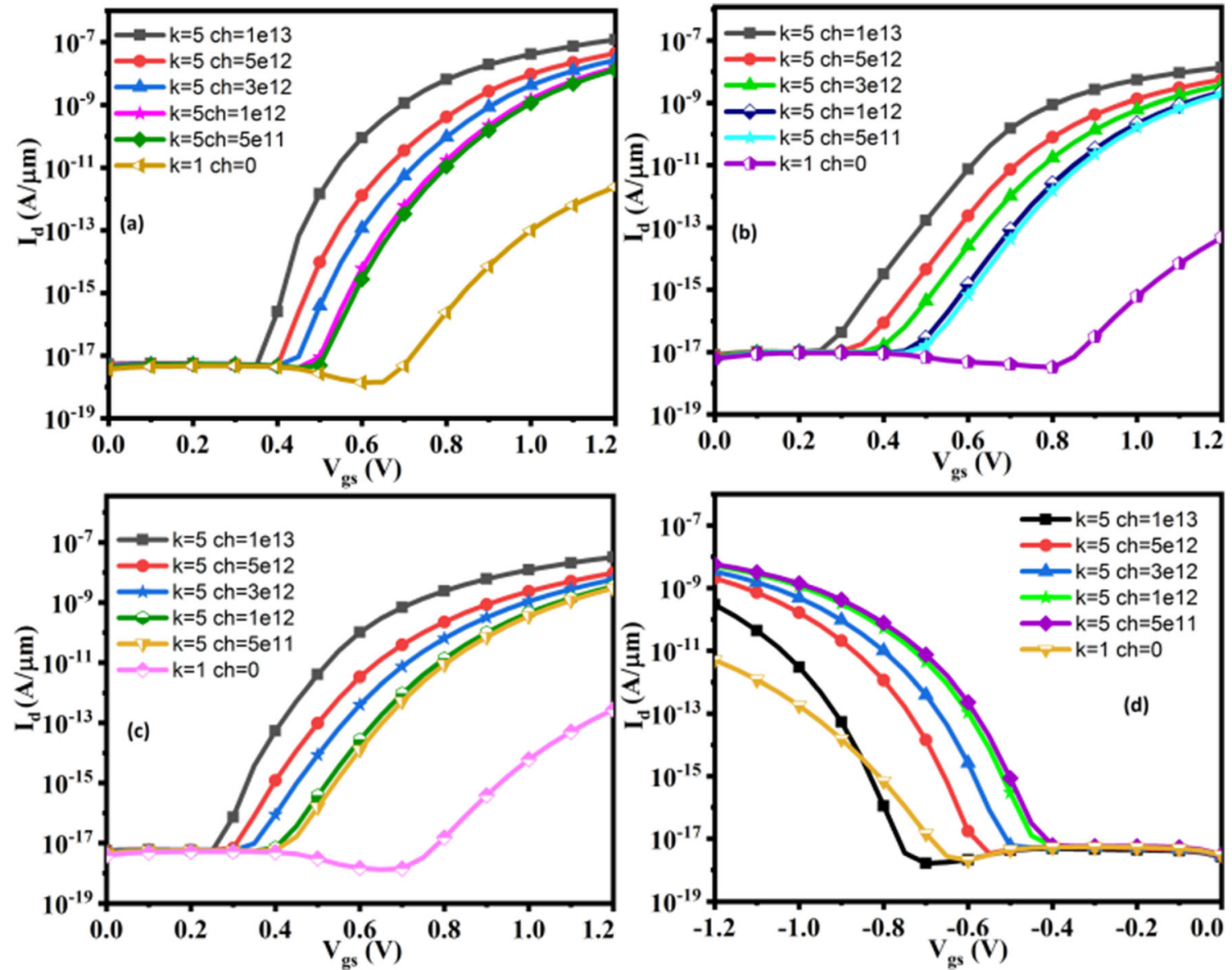

Fig. $7 \mathrm{I}_{\mathrm{d}}-\mathrm{V}_{\mathrm{gs}}$ characteristics of (a) n-PD-DM-TFET (b) n-CP-DM-TFET (c) n-ED-DM-TFET (d) p-ED-DM-TFET based biosensors with positive charge density

current value of all the three devices for positive and negative charged biomolecules are illustrated in Table 3 .

The biomolucule detection quality of a biosensor is obtained though sensitivity analysis. Hence, higher the sensitivity, higher would be the detection probability. The biosensor sensitivity is calculated from Eq. (1).

$\mathrm{S}_{\mathrm{Id}}=\left(\mathrm{Id}^{\mathrm{Bio}}-\mathrm{Id}^{\mathrm{Air}}\right) / \mathrm{Id}^{\mathrm{Air}}$ where $\mathrm{I}_{\mathrm{d}}{ }^{\text {Bio }}$ indicates drain current of the device in the presence of biomolecules and $\mathrm{I}_{\mathrm{d}}{ }^{\mathrm{Air}}$ indicates drain current of the device for vacant cavity.

Greater the difference between the $\mathrm{I}_{\mathrm{d}}{ }^{\text {Bio }}$ and $\mathrm{I}_{\mathrm{d}}{ }^{\mathrm{Air}}$, higher would be the sensitivity. Therefore, increasing the difference between the drain current for $\mathrm{K}=1$ and $\mathrm{K}>1$, increases $\mathrm{I}_{\mathrm{d}}-\mathrm{V}_{\mathrm{gs}}$ sensitivity as shown in Fig. 11(a-d). Table 4 illustrates the $I_{d^{-}}$ $\mathrm{V}_{\mathrm{gs}}$ sensitivity value of all three devices for several neutral
Fig. 8 Energy Band Diagram of (a) n-ED-DM-TFET (b) p-EDDM-TFET based biosensors with positive charge density
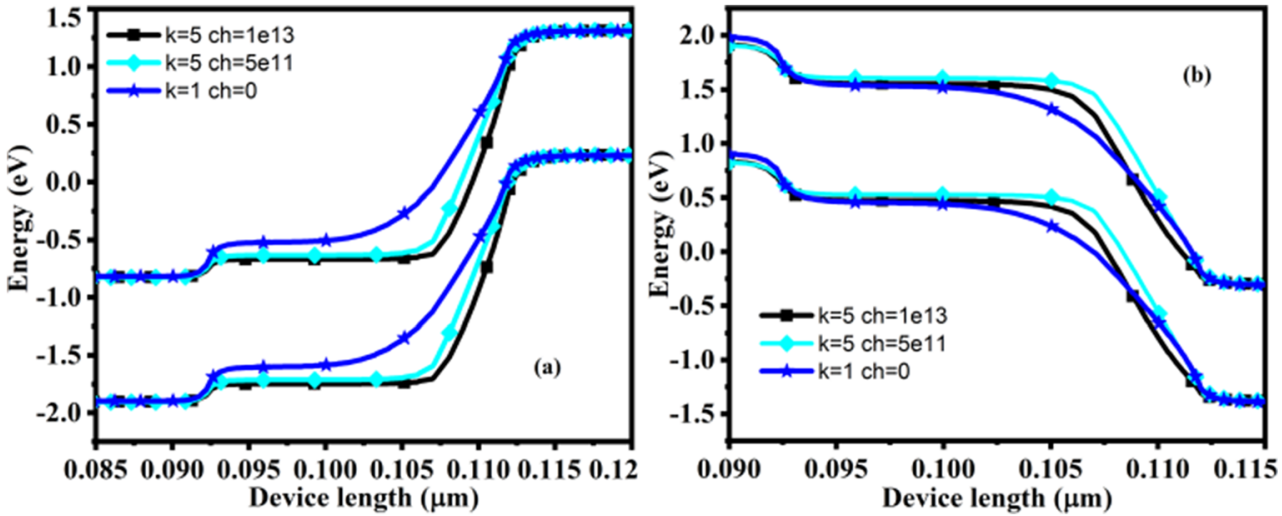

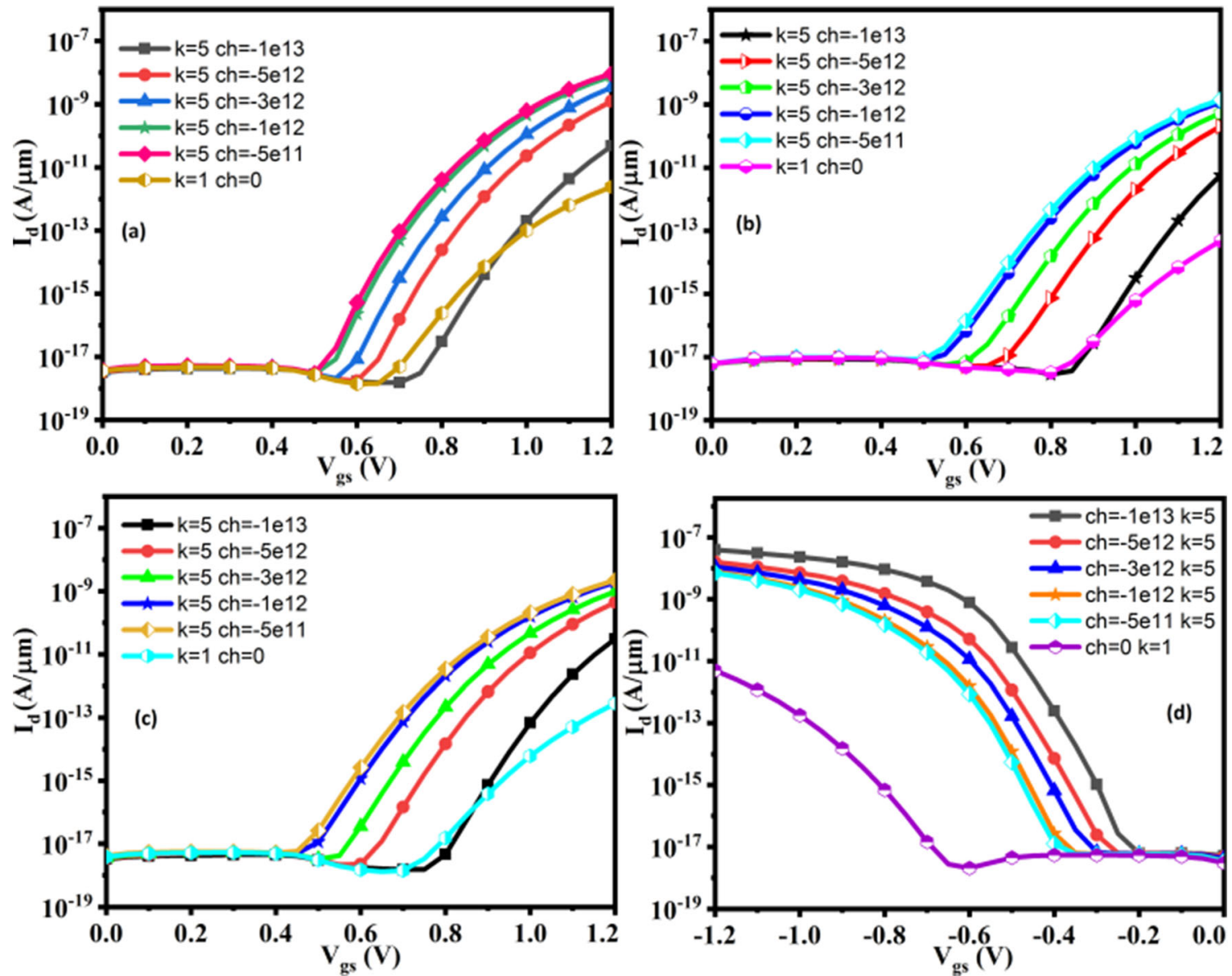

Fig. $9 \mathrm{I}_{\mathrm{d}}-\mathrm{V}_{\mathrm{gs}}$ characteristics of (a) n-PD-DM-TFET (b) n-CP-DM-TFET (c) n-ED-DM-TFET (d) p-ED-DM-TFET based biosensors with negative charge density

biomolecules. In n-PD-DM-TFET and n-CP-DM-TFET based biosensors, the maximum $\mathrm{I}_{\mathrm{d}}-\mathrm{V}_{\mathrm{gS}}$ sensitivity values are $1.07 \times 10^{6}$ and $3.15 \times 10^{7}$ for $\mathrm{K}=12$. In n-ED-DM-TFET, and p-ED-DM-TFET based biosensors, the maximum $\mathrm{I}_{\mathrm{d}}-\mathrm{V}_{\mathrm{gs}}$ sensitivity values are $1.19 \times 10^{7}$ and $5.10 \times 10^{7}$ for $\mathrm{K}=12$.

For positively-charged biomolecules, the $\mathrm{I}_{\mathrm{d}}-\mathrm{V}_{\mathrm{gs}}$ sensitivity of all three devices are shown in Fig. 12(a-d) with the constant $\mathrm{K}=5$ value. Depicted from the difference in drain current, the $\mathrm{I}_{\mathrm{d}}-\mathrm{V}_{\mathrm{gs}}$ sensitivity rises with the increment in positive charge density for $\mathrm{n}$-TFETs but in p-ED-DM-TFET the $\mathrm{I}_{\mathrm{d}}-\mathrm{V}_{\mathrm{gs}}$ sensitivity sensitivity decreases with the increment in positive charge density value of biomolecules. For negative-charged biomolecules, the $\mathrm{I}_{\mathrm{d}}-\mathrm{V}_{\mathrm{gs}}$ sensitivity of all three devices are shown in the Fig. 13(a-d) for same $\mathrm{K}$ value. Here, also due to the drain current difference, $\mathrm{I}_{\mathrm{d}}-\mathrm{V}_{\mathrm{gs}}$ sensitivity decreases with the increment in negative charge density in all three nTFET based biosensor but in p-ED-DM-TFET, $\mathrm{I}_{\mathrm{d}}-\mathrm{V}_{\mathrm{gs}}$ sensitivity rises with the increment in negative charge density. The
Fig. 10 Energy Band Diagram of (a) n-ED-DM-TFET (b) p-EDDM-TFET based biosensors with negative charge density
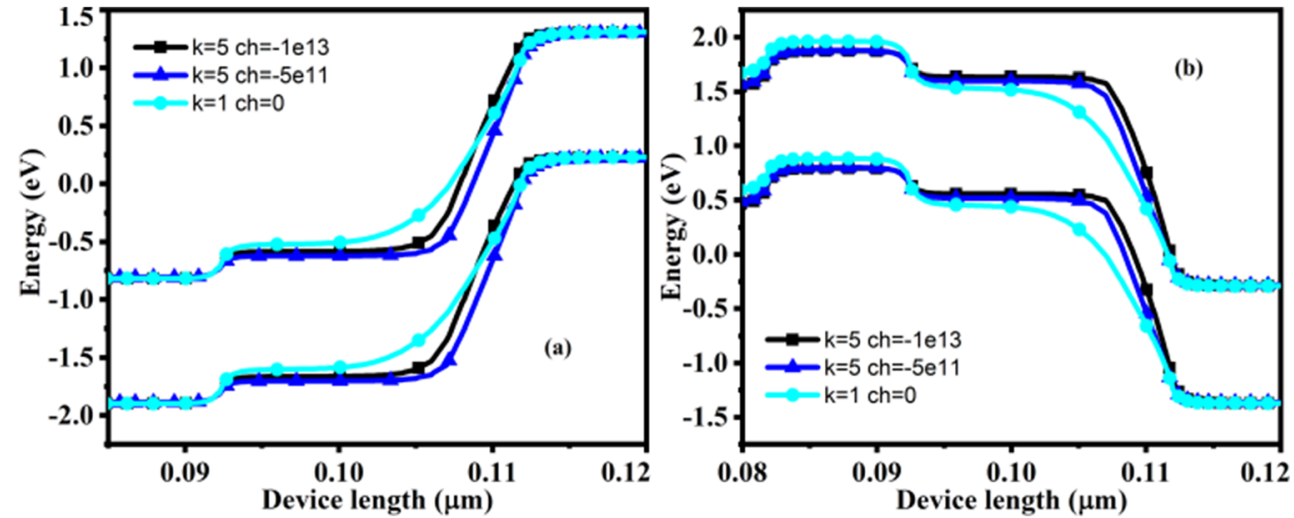
Table 3 Peak current value of PD-DM-TFET, CP-DM-TFET and ED-DM-TFET based biosensors for both positive and negative charged biomolecules

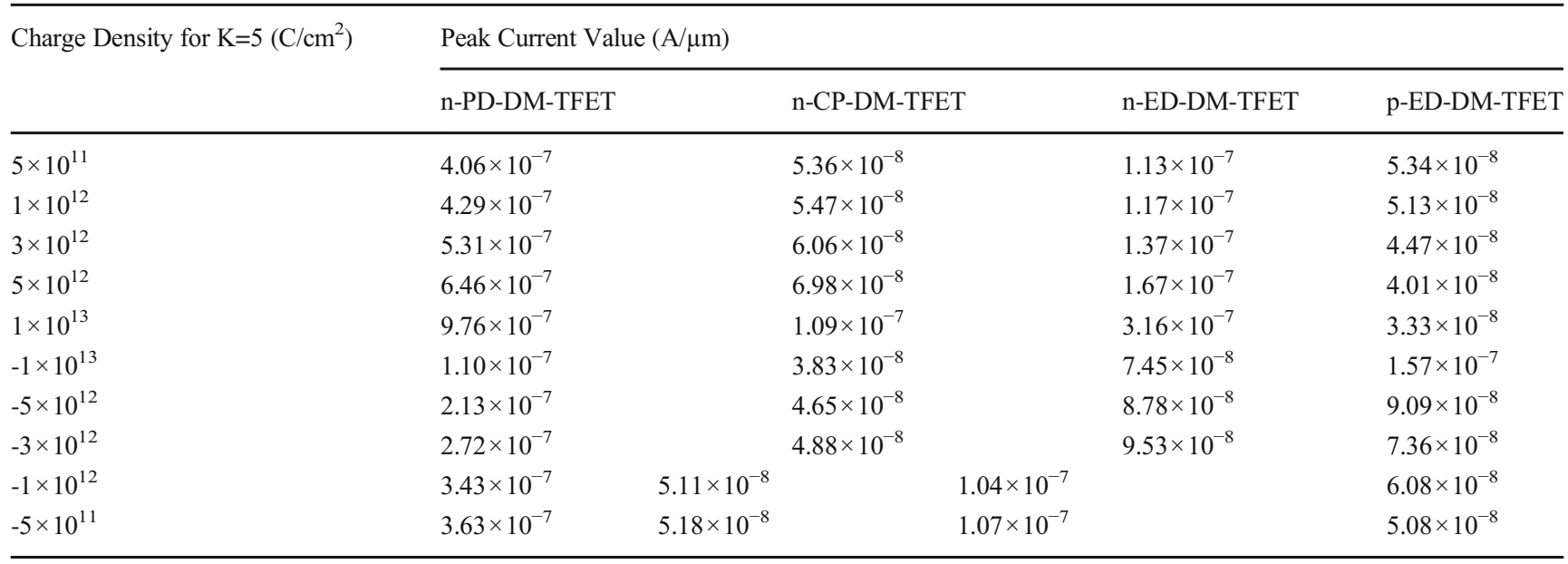

$\mathrm{I}_{\mathrm{d}}-\mathrm{V}_{\mathrm{gs}}$ sensitivity value of three devices for positively and negatively charged biomolecules are shown in Table 5. Results observed in this paper show excellent agreement with
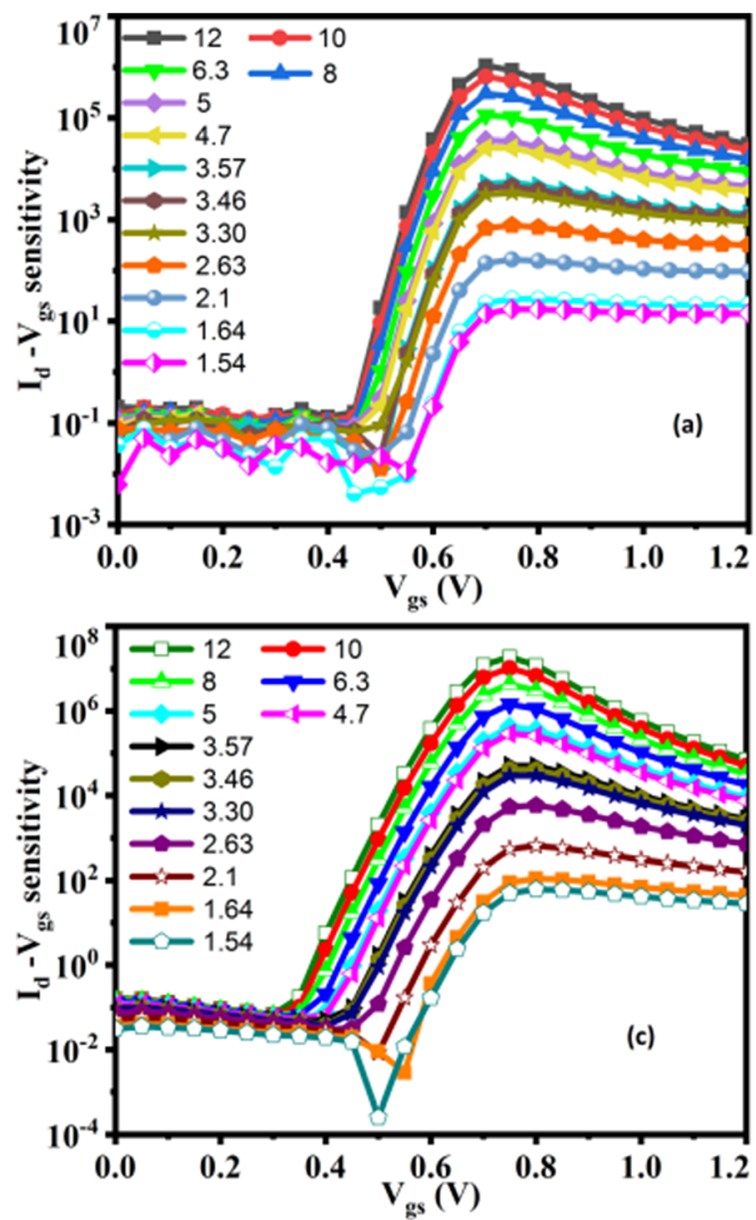

the data presented in [7,16-18], which signifies that the comparative analysis performed in this article is authentic for biomedical applications.
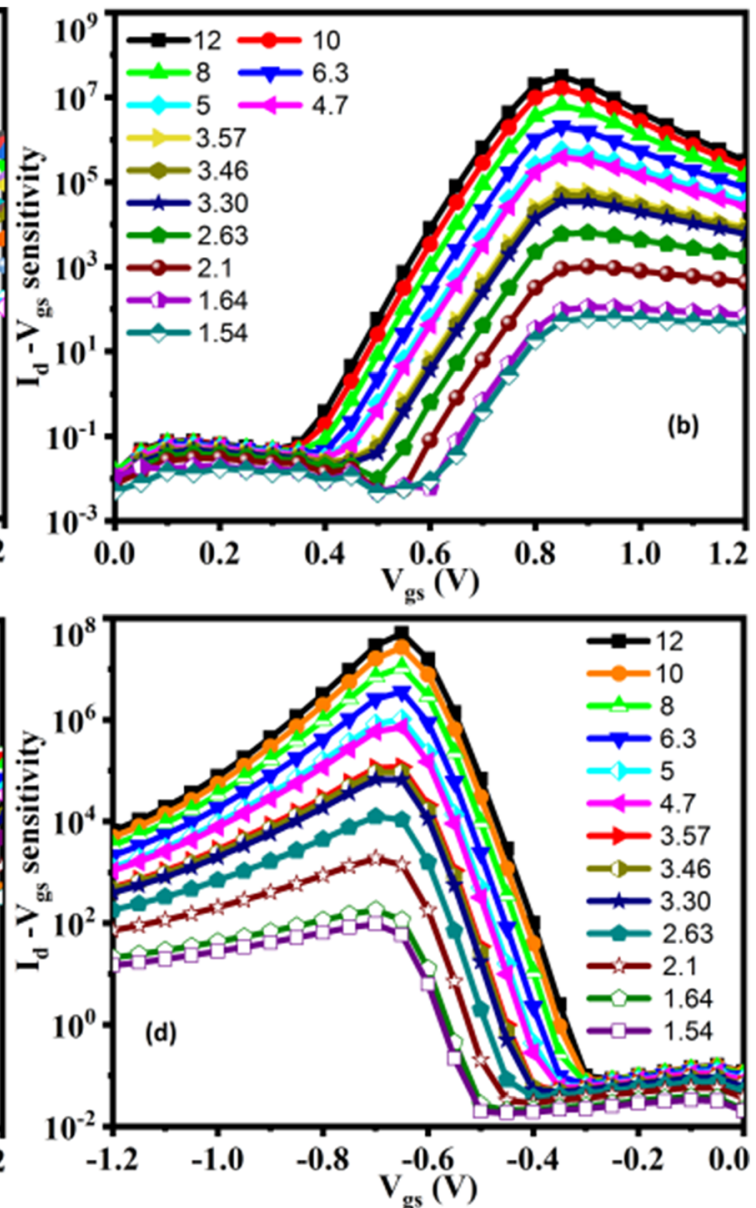

Fig. 11 Characteristics of $\mathrm{I}_{\mathrm{d}}-\mathrm{V}_{\mathrm{gs}}$ sensitivity of (a) n-PD-DM-TFET (b) n-CP-DM-TFET (c) n-ED-DM-TFET (d) p-ED-DM-TFET based biosensors with different value of dielectric constants $(\mathrm{K})$ 
Table $4 \mathrm{I}_{\mathrm{d}}-\mathrm{V}_{\mathrm{gs}}$ sensitivity value of PD-DM-TFET, CP-DM-TFET and ED-DM-TFET based

biosensors for different dielectric constants

\begin{tabular}{lllll}
\hline \multirow{2}{*}{ Dielectric constant $(\mathrm{K})$} & $\mathrm{I}_{\mathrm{d}}-\mathrm{V}_{\mathrm{gs}}$ Sensitivity & & & \\
\cline { 2 - 5 } & n-PD-DM-TFET & n-CP-DM-TFET & n-ED-DM-TFET & p-ED-DM-TFET \\
\hline 1.54 & 17.48 & 61.39 & 62.21 & 97.04 \\
1.64 & 27.88 & 110.98 & 111.74 & 183.49 \\
2.1 & 165.60 & $1.01 \times 10^{3}$ & $0.64 \times 10^{3}$ & $1.8 \times 10^{3}$ \\
2.63 & 782.30 & $6.45 \times 10^{3}$ & $5.89 \times 10^{3}$ & $12.53 \times 10^{3}$ \\
3.30 & $3.41 \times 10^{3}$ & $3.51 \times 10^{4}$ & $2.98 \times 10^{4}$ & $6.69 \times 10^{4}$ \\
3.46 & $4.58 \times 10^{3}$ & $4.97 \times 10^{4}$ & $4.13 \times 10^{4}$ & $9.44 \times 10^{4}$ \\
3.57 & $5.54 \times 10^{3}$ & $6.23 \times 10^{4}$ & $5.13 \times 10^{4}$ & $11.84 \times 10^{4}$ \\
4.7 & $2.61 \times 10^{4}$ & $3.89 \times 10^{5}$ & $2.95 \times 10^{5}$ & $7.21 \times 10^{5}$ \\
5 & $3.63 \times 10^{4}$ & $5.67 \times 10^{5}$ & $4.22 \times 10^{5}$ & $10.40 \times 10^{5}$ \\
6.3 & $1.12 \times 10^{5}$ & $2.06 \times 10^{6}$ & $1.44 \times 10^{6}$ & $3.60 \times 10^{6}$ \\
8 & $3.02 \times 10^{5}$ & $6.53 \times 10^{6}$ & $4.30 \times 10^{6}$ & $10.89 \times 10^{6}$ \\
10 & $6.47 \times 10^{5}$ & $1.64 \times 10^{7}$ & $1.03 \times 10^{7}$ & $2.67 \times 10^{7}$ \\
12 & $1.07 \times 10^{6}$ & $3.15 \times 10^{7}$ & $1.19 \times 10^{7}$ & $5.10 \times 10^{7}$ \\
\hline
\end{tabular}
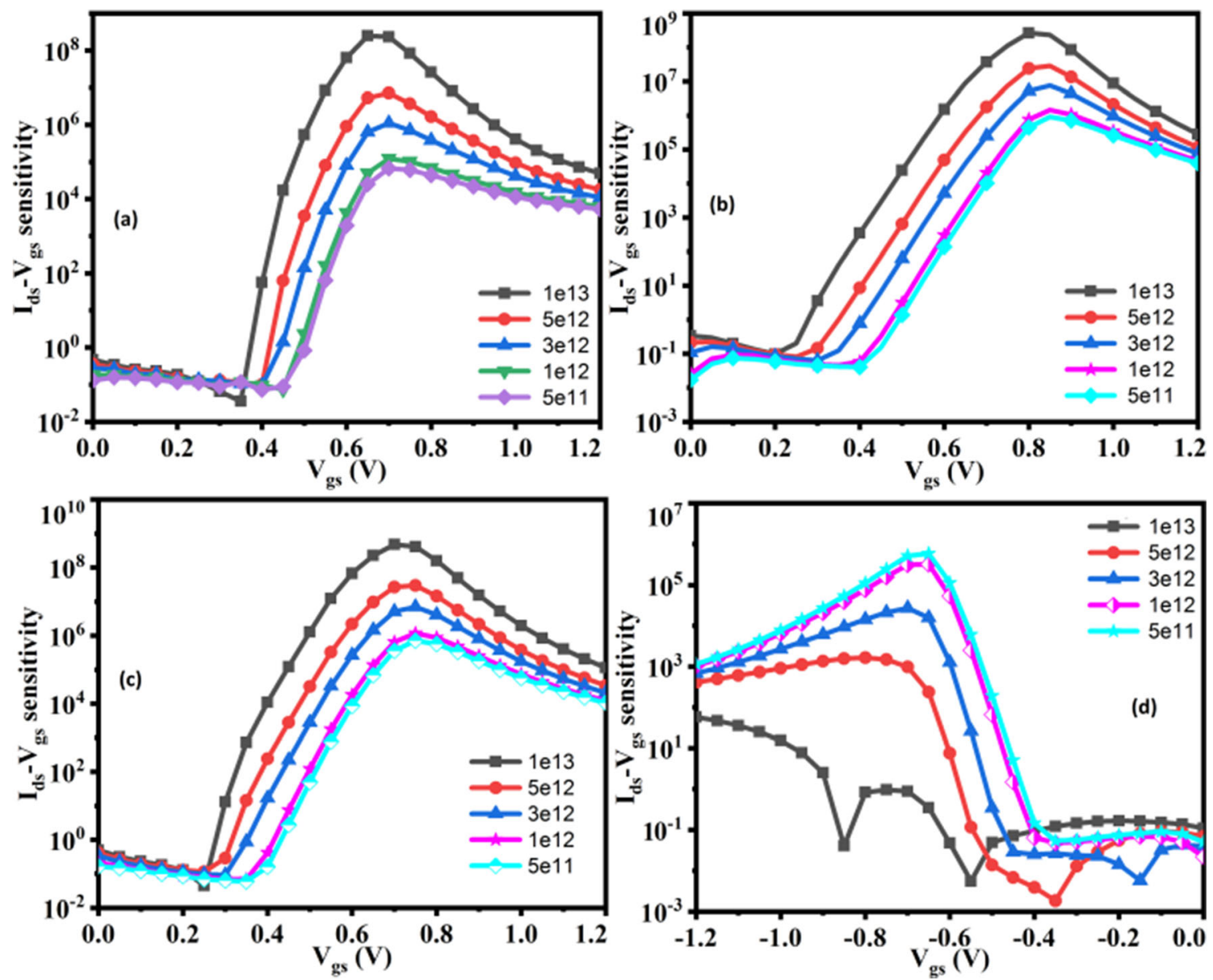

Fig. 12 Characteristics of $\mathrm{I}_{\mathrm{d}}-\mathrm{V}_{\mathrm{gs}}$ sensitivity of (a) n-PD-DM-TFET (b) n-CP-DM-TFET (c) n-ED-DM-TFET (d) p-ED-DM-TFET based biosensors with positive charge density 

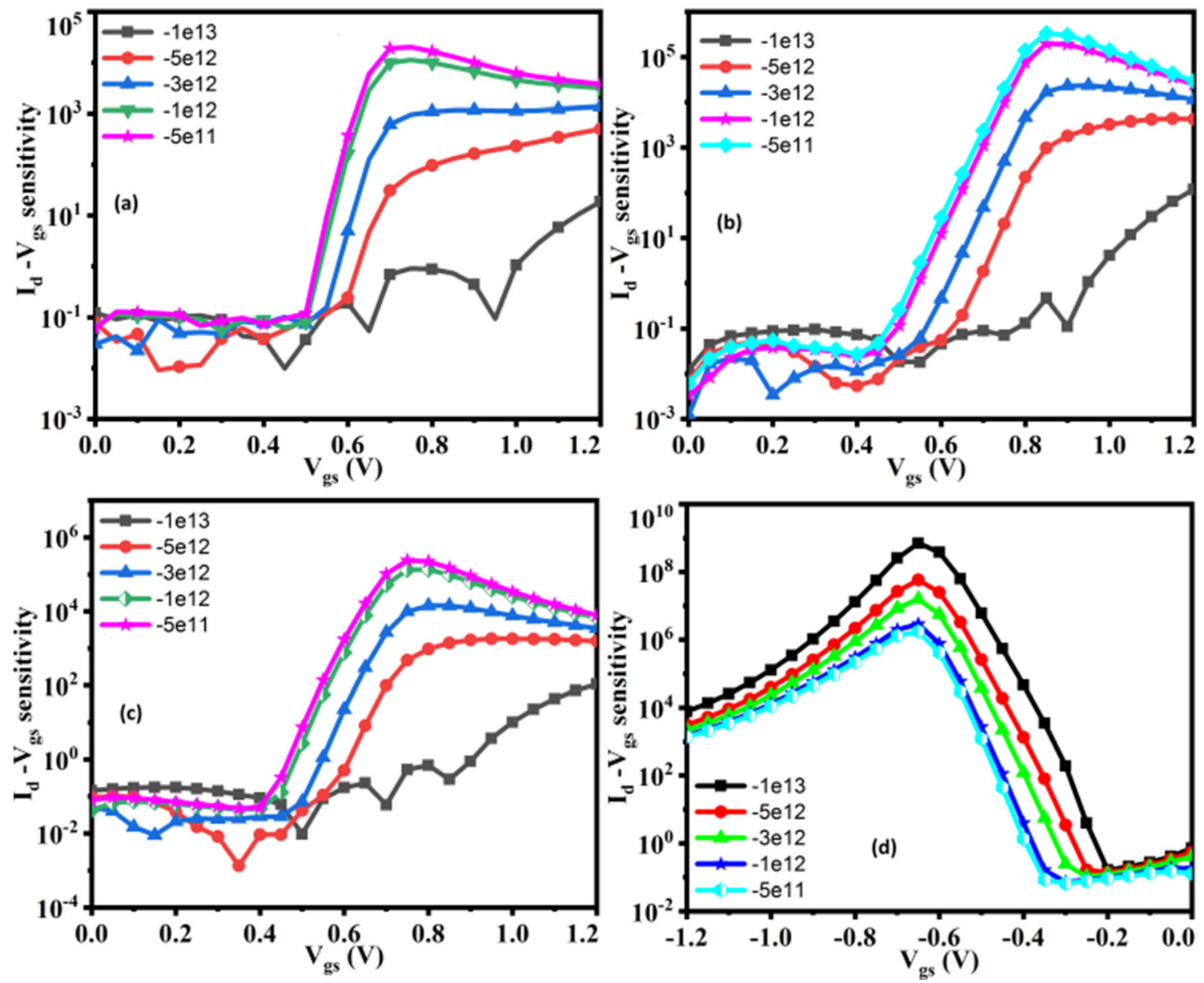

Fig. 13 Characteristics of $\mathrm{I}_{\mathrm{d}}-\mathrm{V}_{\mathrm{gs}}$ sensitivity of (a) n-PD-DM-TFET (b) n-CP-DM-TFET (c) n-ED-DM-TFET (d) p-ED-DM-TFET based biosensors with negative charge density

Table $5 \quad \mathrm{I}_{\mathrm{d}}-\mathrm{V}_{\mathrm{gs}}$ sensitivity value of PD-DM-TFET, CP-DM-TFET and ED-DM-TFET based biosensors for both positive and negative charged biomolecules

\begin{tabular}{|c|c|c|c|c|}
\hline \multirow{2}{*}{$\begin{array}{l}\text { Charge density for } K=5 \\
\left(\mathrm{C} / \mathrm{cm}^{2}\right)\end{array}$} & \multicolumn{4}{|l|}{$\mathrm{I}_{\mathrm{d}}-\mathrm{V}_{\mathrm{gs}}$ sensitivity } \\
\hline & n-PD-DM-TFET & $\begin{array}{l}\text { n-CP-DM- } \\
\text { TFET }\end{array}$ & $\begin{array}{l}\text { n-ED-DM- } \\
\text { TFET }\end{array}$ & $\begin{array}{l}\text { p-ED-DM- } \\
\text { TFET }\end{array}$ \\
\hline $5 \times 10^{11}$ & $6.78 \times 10^{4}$ & $9.28 \times 10^{5}$ & $7.18 \times 10^{5}$ & $5.89 \times 10^{5}$ \\
\hline $1 \times 10^{12}$ & $1.24 \times 10^{5}$ & $1.48 \times 10^{6}$ & $1.19 \times 10^{6}$ & $3.19 \times 10^{5}$ \\
\hline $3 \times 10^{12}$ & $1.12 \times 10^{6}$ & $7.69 \times 10^{6}$ & $7.10 \times 10^{6}$ & $2.72 \times 10^{4}$ \\
\hline $5 \times 10^{12}$ & $7.25 \times 10^{6}$ & $2.86 \times 10^{7}$ & $3.02 \times 10^{7}$ & $1.66 \times 10^{3}$ \\
\hline $1 \times 10^{13}$ & $2.51 \times 10^{8}$ & $2.67 \times 10^{8}$ & $4.77 \times 10^{8}$ & 75.35 \\
\hline$-1 \times 10^{13}$ & 155 & 489.72 & 267.13 & $7.11 \times 10^{8}$ \\
\hline$-5 \times 10^{12}$ & 662.63 & $4.39 \times 10^{3}$ & $1.82 \times 10^{3}$ & $5.86 \times 10^{7}$ \\
\hline$-3 \times 10^{12}$ & $1.39 \times 10^{3}$ & $2.35 \times 10^{4}$ & $1.43 \times 10^{4}$ & $1.59 \times 10^{7}$ \\
\hline$-1 \times 10^{12}$ & $\begin{array}{r}1.13 \times \\
10^{4}\end{array}$ & $1.95 \times 10^{5}$ & $1.36 \times 10^{5}$ & $2.90 \times 10^{6}$ \\
\hline$-5 \times 10^{11}$ & $\begin{array}{r}2.20 \times \\
10^{4}\end{array}$ & $3.37 \times 10^{5}$ & $2.42 \times 10^{5}$ & $1.76 \times 10^{6}$ \\
\hline
\end{tabular}


Table 6 Comparison of the Sensitivity of our proposed work with the data available in literature

\begin{tabular}{|c|c|}
\hline Biosensors & Sensitivity \\
\hline JL-DM-ED-TFET $\left[\mathrm{L}_{\text {cavity }}=10 \mathrm{~nm}, \mathrm{t}_{\text {cavity }}=5 \mathrm{~nm}, \mathrm{k}=10\right][28]$ & $6.89 \times 10^{5}$ \\
\hline CP-DM-JL-TFET $\left[\mathrm{L}_{\text {cavity }}=23 \mathrm{~nm}, \mathrm{t}_{\text {cavity }}=5.5 \mathrm{~nm}, \mathrm{k}=10\right][21]$ & $1.08 \times 10^{8}$ \\
\hline CP-DM-GU-JLTFET [ $\left.\mathrm{L}_{\text {cavity }}=23 \mathrm{~nm}, \mathrm{t}_{\text {cavity }}=5.5 \mathrm{~nm}, \mathrm{k}=10\right]$ [29] & $1.16 \times 10^{4}$ \\
\hline CG-TFET $\left[\mathrm{L}_{\text {cavity }}=25 \mathrm{~nm}, \mathrm{t}_{\text {cavity }}=11 \mathrm{~nm}, \mathrm{k}=10\right][30]$ & $2.32 \times 10^{7}$ \\
\hline DMDG TFET $\left[\mathrm{L}_{\text {cavity }}=150 \mathrm{~nm}, \mathrm{t}_{\text {cavity }}=9 \mathrm{~nm}, \mathrm{k}=10\right][31]$ & $4.82 \times 10^{7}$ \\
\hline This work $\left[\mathrm{L}_{\text {cavity }}=15 \mathrm{~nm}, \mathrm{t}_{\text {cavity }}=3 \mathrm{~nm}, \mathrm{k}=10\right]$ & $1.03 \times 10^{7}$ \\
\hline HM-SE-TFET $\left[\mathrm{L}_{\text {cavity }}=30 \mathrm{~nm}, \mathrm{t}_{\text {cavity }}=5.5 \mathrm{~nm}, \mathrm{k}=5\right][18]$ & $4.1 \times 10^{4}$ \\
\hline DG-TFET $\left[\mathrm{L}_{\text {cavity }}=23 \mathrm{~nm}, \mathrm{t}_{\text {cavity }}=5.5 \mathrm{~nm}, \mathrm{k}=5\right][32]$ & $0.66 \times 10^{3}$ \\
\hline This work $\left[\mathrm{L}_{\text {cavity }}=15 \mathrm{~nm}, \mathrm{t}_{\text {cavity }}=3 \mathrm{~nm}, \mathrm{k}=5\right]$ & $4.22 \times 10^{5}$ \\
\hline
\end{tabular}

Fig. 14 Temperature dependent (a) Drain current variation of EDDM-TFET, and (b) Sensitivity variation for three different TFET configurations
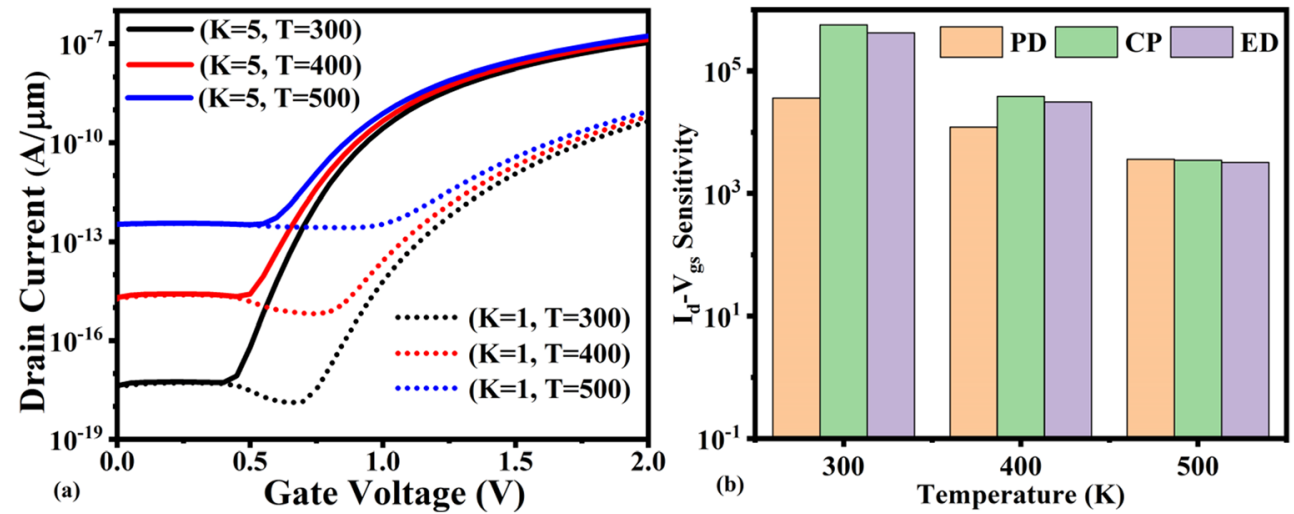

A detailed literature survey has been performed with the $\mathrm{Si}$ based biosensors and it is found that these works has closely matched sensitivity values as shown in Table 6 .

\section{Temperature Dependent Sensitivity}

The temperate dependent sensitivity of the biosensor is also computed for the in-depth analysis of the biosensor. Figure 14(a) shows that as the temperature increases, OFF current increased recombination process in ED-DM-TFET. However, there is no appreciable variation in drain current for higher $\mathrm{V}_{\mathrm{gs}}$ value. Therefore, the biosensor sensitivity depends on both $\mathrm{V}_{\mathrm{gs}}$ and temperature. Hence, Fig. 14(b) shows the peak value of biosensor sensitivity in PD-DM-TFET, CP-DM-TFET and ED-DM-TFET and it is clear that the sensitivity reduces for higher temperature and the variation of sensitivity between the three types of biosensors also reduces with temperature.

\section{Conclusions}

A comparative analysis of PD-DM-TFET, CP-DM-TFET, nED-DM-TFET and p-ED-DM-TFET based biosensors are done in this paper. Both charged and neutral biomolecules are identified and detected by these three devices. Some characteristics like energy band diagram, the surface potential, $\mathrm{I}_{\mathrm{d}}-\mathrm{V}_{\mathrm{gs}}$ (transfer) characteristics and $I_{d}-V_{g s}$ sensitivity are investigated to find better quality biosensor among these three. For neutral biomolecules with $\mathrm{K}=12$ the $\mathrm{I}_{\mathrm{d}}-\mathrm{V}_{\mathrm{gs}}$ sensitivity value of $5.10 \times 10^{7}$ is obtained for $\mathrm{p}$-ED-DM-TFET biosensor which is the maximum among the three nTFET based biosensors. For positively-charged biomolecules with charge density of $1 \times 10^{13} \mathrm{C} / \mathrm{cm}^{2}$, the $\mathrm{I}_{\mathrm{d}}-\mathrm{V}_{\mathrm{gs}}$ sensitivity value of $4.77 \times 10^{8}$ is obtained for $n$-ED-DMTFET biosensor, which is maximum among the three TFET based biosensors. For negatively charged biomolecules with charge density of $-5 \times 10^{11} \mathrm{C} / \mathrm{cm}^{2}$, the $\mathrm{I}_{\mathrm{d}}-\mathrm{V}_{\mathrm{gs}}$ sensitivity value of $1.76 \times 10^{6}$ for $\mathrm{p}$-ED-DM-TFET biosensor is the maximum. So, it could be concluded that ED-DM-TFET based biosensor exhibits better detection and identification capability among the three different configurations of TFET biosensors.

Author Contributions All the authors have contributed to the design, investigation, conceptualization and formal analysis. and design. Author Arpita Biswas prepared the first draft of the manuscript after perfroming the simulation study and validation. Author Chithraja Rajan edited the manuscript after data analysis and validation. D P Samajdar commented on the manuscript and supervised the entire work. All the authors read and approved the final version of the manuscript. 
Data Availability Not applicable.

Code Availability Not Applicable.

\section{Declarations}

Consent to Participate All the authors contributed voluntarily to this work.

Consent for Publication In accordance with the copyright transfer or open access rules.

Conflict of Interest The authors declare that they have no conflict of interest.

Ethics Approval Not Applicable.

\section{References}

1. Drosten C, Drosten S, Preiser W, Werf SVD, Brodt HR, Becker S (2003) Identification of a novel coronavirus in patients with severe acute respiratory syndrome. N Engl J Med 348(20):1967-1976. https://doi.org/10.1056/NEJMoa030747

2. Ali M, Zaki SV, Boheemen TM, Bestebroer ADME, Osterhau, Ron AM, Fouchier (2012) Isolation of a novel coronavirus from a man with pneumonia in Saudi Arabia. N Engl J Med 367(19):18141820. https://doi.org/10.1056/NEJMoa1211721

3. Fuk-Woo Chan J, Yuan S, Kok K-H, Kai-Wang K, To H, Chu J, Yang FX et al (2020) A familial cluster of pneumonia associated with the 2019 novel coronavirus indicating person-to-person transmission: a study of a family cluster. Lancet 395(10223):514-523. https://doi.org/10.1016/S0140-6736(20)30154-9

4. Priyadarshi K, Nag VL, Kombade SP, Gadepalli RS, Misra S, Singh K (2020) Molecular diagnosis of COVID-19: an update and review. Ann Natl Acad Med Sci (India) 3:126-137

5. Kalra S, Kumar MJ, Dhawan A (2019) Reconfigurable FET biosensor for a wide detection range and electrostatically tunable sensing response. IEEE Sens J 20(5):2261. https://doi.org/10.1109/ JSEN.2019.2952333

6. Gandhi R, Chen Z, Singh N, Banerjee K 2011 Vertical Si-nanowire n-type tunneling FETs with low subthreshold swing $(\leq=50 \mathrm{mV} /$ decade) at room temperature,. IEEE Electron Device Letters 32(4): 437-439. https://doi.org/10.1109/LED.2011.2106757

7. Dixit A, Samajdar DP, Chauhan V (2021) Sensitivity Analysis of a Novel Negative Capacitance FinFET for Label-Free Biosensing IEEE Transactions on Electron Devices. 68(10):5204-5210. https://doi.org/10.1109/TED.2021.3107368

8. Rajan C, Samajdar DP (2020) Design principles for a novel lightweight configurable PUF using a reconfigurable FET. IEEE Trans Electron Devices 67(12):5797-5803. https://doi.org/10.1109/TED. 2020.3030868

9. Saha P, Dash DK, Sarkar SK (2019) Nanowire reconfigurable FET as biosensor: Based on dielectric modulation approach. Solid-State Electron 161. https://doi.org/10.1016/j.sse.2019.107637

10. Ghosh C, Dwivedi SMMD, Ghosh A, Dalal A, Mondal A (2019) A novel $\mathrm{Ag}$ nanoparticles/TiO 2 nanowires-based photodetector and glucose concentration detection. Appl Phys A 125(12):1-9

11. Dwivedi SMMD, Ghosh A, Deepthy S, Maji M, Lahiri R, Mondal S, Ghosh C, Dalal A, Mondal A, Ghosh M (2020) Detection technique for vitamin D 3 using Er-doped TiO 2 nanowire-based UV photodetector. J Nanophotonics 14(4):046001. https://doi.org/10. 1117/1.JNP.14.046001
12. Thanihaichelvan MSN, Surendran T, Kumanan U, Sutharsini P, Ravirajan R, Valluvanhhi T, Tharsika (2021) Selective and electronic detection of COVID-19 (Coronavirus) using carbon nanotube field effect transistor-based biosensor: A proof-of-concept study. Mater Today: Proc. https://doi.org/10.1016/j.matpr.2021. 05.011

13. Yadav S, Gedam A, Tirkey S (2020) A dielectric modulated biosensor for SARS-CoV-2. IEEE Sens J. https://doi.org/10.1109/ JSEN.2020.3019036

14. Seo G, Lee G, Kim MJ, Baek S-H, Choi M, Ku KB, Lee C-S et al (2020) Rapid detection of COVID-19 causative virus (SARS-CoV2) in human nasopharyngeal swab specimens using field-effect transistor-based biosensor. ACS Nano 14(4):5135-5142

15. Fathi-Hafshejani P, Azam N, Wang L, Kuroda MA, Hamilton MC, Hasim S, Mahjouri-Samani M (2021)Two-dimensional-materialbasedfield-effect transistor biosensor for detecting COVID-19 virus (SARS-CoV-2). ACS Nano 15(7):11461-11469

16. Verma M, Tirkey S, Yadav S, Sharma D, Yadav DS (2017) Performance assessment of a novel vertical dielectrically modulated TFETbased biosensor. IEEE Trans Electron Devices 64(9): 3841-3848. https://doi.org/10.1109/TED.2017.2732820

17. Agnihotri SK, Samajdar DP, Rajan C, Yadav AS, Gnanesh G (2020) Performance analysis of gate engineered dielectrically modulated TFET biosensors. Int J Electron :1-16. https://doi.org/10. 1080/00207217.2020.1793407

18. Lodhi A, Rajan C, Behera AK, Samajdar DP, Soni D, Yadav DS (2020) Sensitivity and sensing speed analysis of extended nanocavity and source over electrode in $\mathrm{Si} / \mathrm{SiGe}$ based TFET biosensor. Appl Phys A 126(11):1-8. https://doi.org/10.1007/s00339-02004008-0

19. Soni D, Sharma D (2019) Design of NW TFET biosensor for enhanced sensitivity and sensing speed by using cavity extension and additional source electrode. Micro Nano Lett 14(8):901905. https://doi.org/10.1049/mnl.2018.5733

20. Mahalaxmi M, Acharya B, Mishra GP (2020) Design and analysis of dual-metal-gatedouble-cavitycharge-plasma-TFET as a label free biosensor. IEEE Sens J 20(23):13969-13975. https://doi.org/10. 1109/JSEN.2020.2979016

21. Singh D, Pandey S, Nigam K, Sharma D, Yadav DS, Kondekar P (2016) A charge-plasma-baseddielectric-modulated junctionless TFET for biosensor label-free detection. IEEE Trans Electron Devices 64(1):271. https://doi.org/10.1109/TED.2016.2622403

22. Yadav S, Madhukar R, Sharma D, Aslam M, Soni D, Sharma N (2018) A new structure of electrically doped TFET for improving electronic characteristics. Appl Phys A 124(7):517-526. https://doi. org/10.1007/s00339-018-1930-9

23. Sharma D, Singh D, Pandey S, Yadav SKondekar PN (2017) "Comparative analysis of full-gate and short-gate dielectric modulated electrically doped Tunnel-FET based biosensors10.1016/ j.spmi.2017.07.035Sharma D, Singh D, Pandey S, Yadav S, Kondekar PN (2017) Comparative analysis of full-gate and shortgate dielectric modulated electrically doped Tunnel-FET based biosensors. Superlattice Microstruct 111:767-775. https://doi.org/10. 1016/j.spmi.2017.07.035

24. Raad BR, Tirkey S, Sharma D, Kondekar P (2017) A new design approach of dopingless tunnel FET for enhancement of device characteristics. IEEE Trans Electron Devices 64(4):1830-1836. https:// doi.org/10.1109/TED.2017.2672640

25. Chandan BV, Nigam K, Rajan C, Sharma D (2019) A fair comparison of the performance of charge plasma and electrostatic tunnel FETs for low-power high-frequency applications. J Comput Electron 18(4):1201-1206. https://doi.org/10.1007/s10825-01901388-2

26. Boucart K, Ionescu AM (2007)Double-gate tunnel FET with highgate dielectric. IEEE Trans Electron Devices 54(7):1725-1733. https://doi.org/10.1109/TED.2007.899389 
27. latikhameneh H, Ameen TA, Klimeck G, Appenzeller J, Rahman R (2015) Dielectric engineered tunnel field-effect transistor. IEEE Electron Device Lett 36(10):1097-1100. https://doi.org/10.1109/ LED.2015.2474147

28. Bandi V et al (2017) Junctionless based dielectric modulated electrically doped tunnel FET based biosensor for label-free detection. Micro Nano Lett 13(4):452-456

29. Wadhwa G, Raj B (2018) Label free detection of biomolecules using charge-plasma-based gate underlap dielectric modulated junctionless TFET," J Electron Mater 47(8):4683-4693

30. Rupam G et al (2019) Comparative analysis of circular gate TFET and Heterojunction TFET for dielectric-modulated label-free biosensing. IEEE Sens J 19(21):9600-9609
31. Noor SL, Khan MZ (2017) Application of nanocavity embedded dual metal double gate TFET in biomolecule detection," In Humanitarian Technology Conference (R10-HTC) IEEE Region, pp 345-348

32. Shafi N, Sahu C, Periasamy C, Singh J (2017) SiGe source charge plasma TFET for biosensing applications," In Nanoelectronic and Information Systems (iNIS). 2017 IEEE International Symposium, pp 93-98

Publisher's Note Springer Nature remains neutral with regard to jurisdictional claims in published maps and institutional affiliations. 